\title{
Surgical care in the public health agenda
}

\section{Cuidados cirúrgicos na agenda da saúde pública}

Asistencia quirúrgica en la agenda de salud pública

Mário Scheffer 1

Saurabh Saluja 2,3

Nivaldo Alonso 1

doi: 10.1590/0102-311X00104717

\begin{abstract}
The current article examines surgical care as a public health issue and a challenge for health systems organization. When surgery fails to take place in timely fashion, treatable clinical conditions can evolve to disability and death. The Lancet Commission on Global Surgery defined indicators for monitoring sustainable universal access to surgical care. Applied to Brazil, the global indicators are satisfactory, but the supply of surgeries in the country is marked by regional and socioeconomic inequalities, as well as between the public and private healthcare sectors.

\author{
espondence \\ M. Scheffer \\ Faculdade de Medicina, Universidade de São Paulo. \\ Av. Dr. Arnaldo 455, sala 2221, São Paulo, SP \\ 01246-903, Brasil. \\ 1 Faculdade de Medicina, Universidade de São Paulo, São Paulo, \\ Brasil. \\ 2 Program in Global Surgery and Social Change, Harvard \\ Medical School, Boston, U.S.A. \\ 3 Department of Surgery, Weill Cornell Medical College, \\ New York, U.S.A.
}

Operative Surgical Procedures; Global Health; Health Systems 
Access to surgical care has been neglected and unrecognized as a public health problem ${ }^{1}$. Recently, however, it has been incorporated into the global health research agenda, resulting in a growing knowledge base of how surgery can be incorporated into health policy 2,3.

The Lancet Commission on Global Surgery published a report in 2015 that frames the provision of surgical care as an essential part of health systems. The report advocates for the prioritization of surgery and the integration of principles of universality, equity, and justice into surgical systems. Furthermore, the report emphasized the economic argument that surgical care is cost-effective, even in areas of limited resources 2 .

Scientific advances in surgical care - which include both an evolution in procedures and incorporation of new technologies - have improved the diagnosis and treatment of health problems. Yet, these advances have not been shared across different health systems, regions, or socioeconomic groups. In many countries and localities, access to surgical care is limited by the scarcity of surgeons, anesthetists and obstetricians 4,5. Nearly 5 billion people worldwide do not have access to safe, affordable, and timely surgical care, and only $6 \%$ of total surgical procedures occur in the world's poorest countries. Moreover, it is estimated that 16.9 million lives were lost in 2010 due to health problems that required surgical care 6 . Surgical disease manifests across all age-groups and affects the care of many conditions that are prioritized in public health. It plays a critical role in trauma, maternal and child health, and cancer; ultimately, surgery is estimated to play a role in $28-32 \%$ of the global burden of disease 7 .

The unavailability of timely surgical care can transform treatable conditions into diseases with high mortality and morbidity, besides adversely affecting the economy of countries and the wellbeing of populations ${ }^{8}$. For laboring women, unresolved surgical complication can lead to the death of mother and child; congenital malformations, such as cleft lip, and acquired conditions, such as burns, if left uncorrected, can harm the cognitive and social development of individuals; and delays in trauma care and fractures can leave young people disabled and economically unproductive for life.

The surgical system is ample and includes professionals, institutions, as well as public and private financial sectors responsible for service delivery. The surgical system is involved across the spectrum of disease, ranging from prevention to diagnostics to treatment and palliation. It requires human resources, consumables and equipment, which are used in the preoperative evaluation of patients' health and risk factors, the intraoperative period during which procedure occurs, and the postoperative period. To this end, the surgical system requires infrastructure consisting of surgical facilities, blood supply, referral systems as well as human resources capable of anesthetic, surgical and obstetric care. This includes physicians, surgical teams, nursing personnel, and technicians responsible for radiology, pathology, and laboratory.

The lack of attention to surgical care in health-systems and health policy research agendas may be linked to the mistaken notion that surgical care applies to only a small portion of diseases, that it is prohibitively complex, or not cost-effective. It may also be the consequence of choices by governments that favor healthcare models that neglect the role of surgery in health-systems. The result is policies and funding for public health research that neglect surgical care, especially in developing countries.

While surgical care is often cost-effective at the system level, at the individual level it often includes costly procedures. It is responsible for much of the remuneration of doctors and hospitals in both public and private systems and it interfaces with the medical industry, including pharmaceutical companies and equipment and supply companies. The provision of surgical care is therefore sensitive to individual health demands, physician decisions, and private business interests. It must also be the object of collective management - i.e. it must be structured by health systems. The role of the state is, therefore, fundamental to ensure the delivery and function of surgical services and the availability of human resources.

Part of that role includes regulation and standardization of care. It has been shown that patients with similar health problems that require the same surgical intervention are treated differently from one country to another and even within the same country 9,10. For example, the number of patients admitted for surgery is twice as high in Germany, Australia, and Israel than in Canada, Spain, and Portugal. A patient is three times more susceptible to have a cardiac revascularization in Germany and Israel when compared with other countries. In France 11, an analysis of ten surgical interventions 
showed persistent variation in medical practice, both at the regional level and within departments. This applied to both the frequency and effectiveness of interventions.

Barriers to access, variations in practice patterns and unavailability of care create ethical, therapeutic, and economic problems for the health system. To understand the scale of these problems, more studies using public information on the availability of surgical services, their geographic variation, as well as different practice patterns are needed.

In 2015, the Lancet Commission on Global Surgery selected six indicators and a framework for a national surgical plan to help evaluate the current state of surgical and anesthesia systems. The reason to define these indicators was to allow each country to measure its current state of surgical service provision and, with this information, form a national surgical plan. The indicators presented by the commission include timely access to essential surgical care, adequacy of surgical workforce, volume of surgical procedures, post-operative mortality rate, and protection against impoverishing expenditures owing to surgical care.

Recently applied to Brazil, these indicators proved to be useful and revealed a country with generally adequate parameters but with immense geographic inequality and regional differences in the ability to offer surgery and anesthesia. With a workforce density (defined as surgeons, anesthetists and obstetricians) of 34.7 per 100,000 habitants, a public surgical volume of 4,433 surgical procedures per 100,000 habitants, and post-operative mortality rate of $1.71 \%$, the country achieved indicators close to suggested values. However, there are regional disparities in each of the suggested indicators, with some regions and states having indicators close to those of low-income countries 12 . The density of the surgical workforce varies from 20.55 per 100,000 people in the North up to 61.94 per 100,000 people in the South. Overall, anesthetists make up 19.8\% of the surgical workforce, which is right at the worldwide mean of $20 \%$. However, in the states of Rondônia, Roraima, Amapá, Maranhão and Piauí, anesthesiologists make up around $14 \%$ or less of the surgical workforce 13. Brazil has a surgical workforce that easily exceeds the suggested benchmark of 20 surgical specialists per 100,000 habitants. However, more than $70 \%$ of these professionals were in large cities where only $24 \%$ of the population lives. Moreover, these professionals are largely concentrated in private health institutions, which only serve the quarter of the Brazilian population that has private health insurance.

In December 2016, a meeting in São Paulo addressed surgical care provision and assessed the viability of implementing national surgical plans throughout Latin America. At this meeting, a pilot study that analyzed surgical system in the state of Amazonas was presented 14. The study used qualitative methods to interview surgeons, anesthetists, and other health professionals from hospitals in the interior, aiming to understand the Lancet Commission on Global Surgery indicators and access emergency surgeries, such as cesarean section, open fracture, and laparotomy. These interviews revealed a severe lack of health professionals, resulting in non-surgeons providing surgical care, and non-physicians performing medical procedures. Many interviewees addressed poor work conditions, quality of life, and remuneration as reasons for the unavailability of health professionals.

The availability of surgical services, or lack therein, is an inseparable part of the Brazilian health system that is susceptible to the financing, function, and organization of the system as a whole. Access to healthcare is not simply related to the availability of health services, but is also influenced by social determinants of individuals and by their locale of residence 15 . The wait-time to receive specialized medical care and elective surgery is shorter for people with higher incomes and longer for those of lower socioeconomic status, even after adjusting for age, sex, education, and state of health. Further, when evaluating hospitalizations in Brazil, some of which are for surgical procedures, there has been a trend for many years (from 1998 to 2013) towards decreasing direct payments from patients, decreasing hospitalizations attributed to the Brazilian Unified National Health System (SUS), and increasing hospitalizations for private health plans 16 .

The SUS, which provides free at point of service universal healthcare, prevents and treats diseases, besides having a complex mix of directly and indirect administration by the federal government, states, and municipalities. It is organized in a regionalized and hierarchical form and relies on complementary private initiatives towards the provision or management of healthcare 17.

Approximately one in four Brazilians has private health insurance, which, in many cases, covers surgery. However, this population also uses surgical services offered by SUS, whether in prevention campaigns, urgent or emergent situations such as motor vehicle accidents, for surgeries not covered 
by private health plans, or in the case of cancelled insurance due to unemployment (more than $80 \%$ of the insurance market is comprised of plans offered by employers). While most primary care and emergency services are public, hospitals, diagnostic services, and radiology are mostly private, and private expenditure represents approximately $54 \%$ of total healthcare expenditure in Brazil 18 . This result is a concentration of resources in a small private sector that selects against high-risk patients and procedures and an under-resourced public sector tasked with the comprehensive care of the population.

This manifests a distortion in the provision of services. For example, the public availability of midcomplexity care, which includes ambulatory surgery, is insufficient in Brazil. These services are mostly offered in the private sector and primarily serve patients with health plans that reimburse more than SUS does for surgical procedures. Whether in free-standing facilities, adjacent to specialty clinics, or in hospitals with surgical centers, ambulatory surgery is characterized by same-day discharge. Ambulatory surgery can be used in varied situations, such as cataract operations, knee arthroscopy, varicose vein surgery, etc. It has the benefit of using fewer resources, reducing cost, decreasing waitlists, improving patient-satisfaction, and limiting exposure to nosocomial infections - outcomes that should guide the expansion of such services in the public health system.

While ambulatory surgery represents a potential for improving the delivery of public surgical services in Brazil, the hospital network remains the backbone of surgical care delivery. However, this network is considered heterogeneous and inefficient and relies on a predominance of small to mid-sized hospitals (up to 50 beds), with outdated infrastructure, that provide inadequate service to the population ${ }^{19}$. There are disparities among regions and between public and private sectors, with the paradoxical result of having idle beds in some hospitals whilst there is overflow in others. This is driven, in part, by differential pricing for the same type of hospitalization or procedure. In Brazil, only $35 \%$ of hospital beds are in public hospitals with the remaining 65\% in the private sector, with many of these hospital networks organized into private financial groups. Since the public availability is insufficient, SUS must purchase from the private sector. Thus, providers and purchasers of surgical services compete, and governments and health plans pay differential rates for hospitalizations and surgeries. Surgeons and anesthetists have dual practices, but often concentrate their time in the private sector due to better work conditions and remuneration. The result is an exacerbated inequality in utilization of surgical services, especially for elective care.

The future of surgical care in Brazil depends on the sustainability of SUS, which, in turn, depends on overcoming political and economic crises that have afflicted the country since 2013 . These crises have resulted in fiscal adjustments, diminishing resources for public health and the emergence of proposals to expand the private health market by developing "accessible" or "popular" plans 20, offer reduced coverage, and may not cover hospitalizations or surgeries. While this may be an appealing approach to austerity, it may paradoxically result in longer surgical wait-times and continued overburdening of SUS, especially for surgical conditions.

Surgical care without a doubt must be incorporated into all levels of the health system, and countries must integrate safety, quality and cost-effectiveness in the provision of services. To do so, data collection systems are needed to evaluate and monitor clinical processes, costs, and outcomes. These systems will also shed light on the human and material resources needed for care delivery, the complexity of public and private financing and management, and the way in which surgical services are organized for, provided for, accessed by, and used by the population.

The challenge of supporting a research agenda that brings surgical care closer to public health, connects national and global problems, and finds ways to overcome inequalities to fully guarantee the right to healthcare remains. 


\section{Contributors}

The authors contributed equally in the production of the paper.

\section{References}

1. Farmer PE, Kim JY. Surgery and global health: a view from beyond the OR. World J Surg 2008; 32:533-6.

2. Meara JG, Leather AJ, Hagander L, Alkire BC, Alonso N, Ameh EA, et al. Global surgery 2030: evidence and solutions for achieving health, welfare, and economic development. Lancet 2015; 386:569-624.

3. Dare AJ, Grimes CE, Gillies R, Greenberg SL, Hagander L, Meara JG, et al. Global surgery: defining an emerging global health field. Lancet $2014 ; 384: 2245-7$.

4. Holmer H, Lantz A, Kunjumen T, Finlayson S, Hoyler M, Siyam A, et al. Global distribution of surgeons, anaesthesiologists, and obstetricians. Lancet Glob Health 2015; 3 Suppl 2: S9-11.

5. Lantz A, Holmer H, Finlayson S, Ricketts TC, Watters D, Gruen R, et al. International migration of surgeons, anaesthesiologists, and obstetricians. Lancet Glob Health 2015; 3 Suppl 2:S11-2.

6. Weiser TG, Regenbogen SE, Thompson KD, Haynes AB, Lipsitz SR, Berry WR, et al. An estimation of the global volume of surgery: a modelling strategy based on available data. Lancet 2008; 372:139-44.

7. Shrime MG, Bickler SW, Alkire BC, Mock C. Global burden of surgical disease: an estimation from the provider perspective. Lancet Glob Health 2015; 3 Suppl 2:S8-9.

8. Murray CJ, Vos T, Lozano R, Naghavi M, Flaxman AD, Michaud C, et al. Disability-adjusted life years (DALYs) for 291 diseases and injuries in 21 regions, 1990-2010: a systematic analysis for the Global Burden of Disease Study 2010. Lancet 2012; 380:2197-223.

9. Organisation for Economic Co-operation and Development. Geographic variations in health care: what do we know and what can be done to improve health system performance? Paris: OECD Publishing; 2014. (OECD Health Policy Studies).

10. Corallo AN, Croxford R, Goodman DC, Bryan EL, Srivastava D, Stukel TA. A systematic review of medical practice variation in OECD countries. Health Policy 2014; 114:5-14.

11. Institut de Recherche et Documentation en Économie de la Santé. Atlas des variations de pratiques médicales recours à dix interventions chirurgicales. Paris: Institut de Recherche et Documentation en Économie de la Santé; 2016.

12. Massenburg BB, Saluja S, Jenny HE, Raykar NP, Ng-Kamstra J, Guilhoux AGA, et al. Assessing the Brazilian surgical system with six surgical indicators: a descriptive and modelling study. BMJ Glob Health 2017; 2:e000226.

13. Scheffer MC, Gilloux AGA, Matijasevich A, Saluja S, Alonso N. The state of the surgical workforce in Brazil. Surgery 2017; 161: 556-61. 
14. Saluja S, Citron I, Amundson J, dos Santos Souza JE, Scheffer M, Ferreira RV, et al. Health care leaders develop strategies for improving acess to surgical care in Latin America. Bull Am Coll Surg 2017; 102:22-7.

15. Travassos C, Oliveira EXG, Viacava F. Desigualdades geográficas e sociais no acesso aos serviços de saúde no Brasil: 1998 e 2003. Ciênc Saúde Coletiva 2006; 11:975-86.

16. Viacava F, Bellido JG. Health, access to services and sources of payment, according to household surveys. Ciênc Saúde Coletiva 2016; 21:351-70

17. Secretaria de Gestão Estratégica e Participativa, Ministério da Saúde. Regulamentação da Lei 8.080 para fortalecimento do Sistema Único da Saúde: decreto 7508, de 2011. Rev Saúde Pública 2011; 45:1206-7.

\section{Resumo}

O presente artigo aborda os cuidados cirúrgicos como um problema de saúde pública e um desafio para a organização dos sistemas de saúde. Se cirurgias não ocorrerem em tempo adequado, situações clínicas tratáveis podem evoluir para incapacidades e mortes. A Lancet Commission on Global Surgery definiu indicadores para o monitoramento do acesso universal sustentável à assistência cirúrgica. Aplicados ao Brasil, os indicadores globais são satisfatórios, porém a oferta de cirurgias no País é marcada por desigualdades entre regiões, entre estratos socioeconômicos e entre os setores público e privado da saúde.

Procedimentos Cirúrgicos Operatórios; Saúde Global; Sistemas de Saúde
18. Paim J, Travassos C, Almeida C, Bahia L, Macinko J. The Brazilian health system: history, advances, and challenges. Lancet 2011; 377:1778-97.

19. Brito LAL, Malik AM, Brito E, Bulgacov S, Andreassi T. Práticas de gestão em hospitais privados de médio porte em São Paulo, Brasil. Cad Saúde Pública 2017; 33:e00030715.

20. Bahia L, Scheffer M, Dal Poz MR, Travassos C. Private health plans with limited coverage: the updated privatizing agenda in the context of Brazil's political and economic crisis. Cad Saúde Pública 2016; 32:e00184516.

\section{Resumen}

El presente artículo aborda la asistencia quirúrgica como un problema de salud público y un desafío para la organización de los sistemas de salud. Si no se ejecutan cirugías en el momento adecuado, situaciones clinicas tratables pueden evolucionar en incapacidades y muertes. La Lancet Commission on Global Surgery definió indicadores para la supervisión del acceso universal sostenible a la asistencia quirúrgica. Aplicados a Brasil, los indicadores globales son satisfactorios, aunque la oferta de cirugías en el país está marcada por desigualdades entre regiones, entre estratos socioeconómicos y entre los sectores público y privado de salud.

Procedimientos Quirúrgicos Operativos; Salud Global; Sistemas de Salud 